\title{
Re-examining the Higher Predictive Power of D/P and E/P during Recessions
}

\author{
Frederick Adjei* \\ Economics and Finance Department, Southeast Missouri State University, One University Plaza, Cape Girardeau \\ *Corresponding author: fadjei@semo.edu
}

Received November 18, 2018; Revised January 03, 2019; Accepted January 19, 2019

\begin{abstract}
In this study, we examine the differential predictive power of the dividend-price ratio $[\mathrm{D} / \mathrm{P}]$ and the earnings-price ratio $[\mathrm{E} / \mathrm{P}]$ for future stock returns during recessions versus during expansionary periods. We find that dividends do not decrease but prices decrease from the expansion periods to the recession periods resulting in the $\mathrm{D} / \mathrm{P}$ increase during recessions. This increase in $\mathrm{D} / \mathrm{P}$ during recessions is correlated with the increase in market returns following recessions. However, we find no significant difference in means of E/P between recession and expansion periods. Additionally, we find that the explanatory power of $\mathrm{D} / \mathrm{P}$ and $\mathrm{E} / \mathrm{P}$ for future market returns varies with time. $\mathrm{D} / \mathrm{P}, \mathrm{E} / \mathrm{P}$, and future market returns move together during the first two subperiods, peaking toward the end of recession periods. Particularly, D/P and future market return trend differently during expansion periods, but the trends are reset into tandem during recession periods, also explain why predictive regressions in studies using the full sample period present conflicting results.
\end{abstract}

Keywords: predictive power of $D / P$ and $E / P$

Cite This Article: Frederick Adjei, "Re-examining the Higher Predictive Power of D/P and E/P during Recessions.” Journal of Finance and Economics, vol. 7, no. 1 (2019): 36-41. doi: 10.12691/jfe-7-1-4.

\section{Introduction}

Extant research such as Rapach, Strauss, and Zhou [1] and Dangl and Halling [2] document that excess stock return predictability by the dividend-price ratio $[\mathrm{D} / \mathrm{P}]$ and the earnings-price ratio $[\mathrm{E} / \mathrm{P}]$ concentrates mostly in recessions; such valuation ratios have higher predictive power during recessions. However, the explanation for the higher predictive power remains ambiguous.

In this study, we demonstrate and document that the higher predictive power of recession period $\mathrm{D} / \mathrm{P}$ and $\mathrm{E} / \mathrm{P}$ for future stock returns can be explained by a far more elemental phenomenon; the nature of the computation of the $\mathrm{D} / \mathrm{P}$ and $\mathrm{E} / \mathrm{P}$ ratios. The computation of the dividends in $\mathrm{D} / \mathrm{P}$ and the earnings in $\mathrm{E} / \mathrm{P}$ for monthly observations use linear interpolation; curve fitting using a mathematical model to produce data points within a discrete set of collected data. For instance, Robert Shiller's valuation ratios monthly data (which is used in most of the valuation studies), computes S\&P 500 monthly dividends and earnings data from the S\&P 500 quarterly totals for data from 1926 to present, generating monthly observations by linear interpolation. The result is smoothed or curved monthly dividend or monthly earnings which do not reflect the intertemporal corporate policy or performance.

We provide an empirical explanation for the higher predictive power. We base our explanation on the nature of the computation of the dividend-price ratio $[\mathrm{D} / \mathrm{P}]$ and the earnings-price ratio $[\mathrm{E} / \mathrm{P}]$. Particularly, we empirically validate the conjecture that recessions reset the correlation between D/P (and also E/P) and future stock returns. We document that dividends do not decrease but prices decrease from the expansion periods to the recession periods resulting in the $\mathrm{D} / \mathrm{P}$ increase during recessions. This increase in D/P during recessions is correlated with the increase in market returns following recessions and explains the documented predictive power of $\mathrm{D} / \mathrm{P}$ for future returns.

Additionally, we uncover that there is no significant difference in means of $\mathrm{E} / \mathrm{P}$ between recession and expansion periods. However, for the third subperiod of our sample period: January, 1986 to December, 2016, earnings as well as prices decrease from the expansion periods to the recession periods resulting in the $\mathrm{E} / \mathrm{P}$ decrease. Particularly, we find that the explanatory power of $\mathrm{D} / \mathrm{P}$ and $\mathrm{E} / \mathrm{P}$ for future market returns varies with time. $\mathrm{D} / \mathrm{P}$, $\mathrm{E} / \mathrm{P}$, and future market returns move together during the first two subperiods, peaking toward the end of recession periods. The trends in $\mathrm{D} / \mathrm{P}$ and $\mathrm{E} / \mathrm{P}$ : the decrease in dividends relative to prices, and the decrease in $\mathrm{E} / \mathrm{P}$ during recessions in the last 31 years [1986 to 2016], explain the differential predictive powers and also explain why predictive regressions in studies using the full sample period present conflicting results.

\section{Literature Review}

There is extensive research on the predictive power of the dividend-price ratio $[\mathrm{D} / \mathrm{P}]$ and the earnings-price ratio 
[E/P] for future stock returns [3,4,5,6]. Particularly, Rapach, Strauss, and Zhou [1] and Dangl and Halling [2] find that $\mathrm{D} / \mathrm{P}$ and $\mathrm{E} / \mathrm{P}$ have higher predictive power during recessions.

Several explanations, motivated by many theories, have been postulated for this phenomenon. One popular theory is the learning asymmetries theory. Cujean and Hasler [7] construct an equilibrium model in an attempt to explain why future stock return predictability concentrates in recessions, and find that differences in investor learning speeds increases and culminates in opinion polarization during recessions. Their model shows a link between the increased investor disagreements during recessions and future stock returns and presents results showing a higher concentration of return predictability during recessions. Van Nieuwerburgh and Veldkamp [8], find a correlation among the rate of information flow, the content of economics signals, and the business cycle, leading to information asymmetries correlated with the business cycle.

Another theory explaining the higher predictive power of valuation ratios during recessions is that of mean reversion. Coakley and Fuertes [9] document that the change in valuation ratios during bear markets is partly due to the fact that valuation ratios mean revert so that in the long run prices reflect the value of fundamentals. And Gray [10] finds that mean-reverting periods are notably correlated with recessions.

From an investor sentiment perspective, Lee, Jiang and Indro [11] contend that investor sentiment is positively correlated with movements in excess returns and is a priced risk factor. Lee et al. present that bullish changes in investor sentiment lead to predictions of decreased volatility and elevated future excess returns and the opposite is true for bearish changes in investor sentiment. It is thus reasonable to construe that the valuation ratios could be decoupled from firm fundamentals due, at least in part, to investor sentiment, and this may explain the differential predictive power during recessions.

Empirically, Kim, Lim, and Shamsuddin [12] find evidence that future stock return predictability is determined by changing market conditions, particularly, evolving market efficiency, and find that stock return predictability is lower during asset price bubbles than during normal times.

\section{Hypothesis Development}

As discussed earlier, the computation of the monthly stock price in $\mathrm{D} / \mathrm{P}$ and $\mathrm{E} / \mathrm{P}$ for monthly data is by a monthly averaging of daily closing prices, reflecting the current state of the market. Consequently, during a recession the decrease in stock prices which is the denominator in $\mathrm{D} / \mathrm{P}$ and $\mathrm{E} / \mathrm{P}$, results in an increase in $\mathrm{D} / \mathrm{P}$ and $\mathrm{E} / \mathrm{P}$. As the economy improves, stock returns will inevitably be higher than stock returns during the recession, and these higher returns will be correlated with the higher $\mathrm{D} / \mathrm{P}$ and $\mathrm{E} / \mathrm{P}$ from the recession period.

Following the recession, stock prices increase and revert to their random jumps decreasing the correlation between $\mathrm{D} / \mathrm{P}$ (and $\mathrm{E} / \mathrm{P}$ ) and future stock returns. This may explain why future stock returns are higher correlated with recession period $\mathrm{D} / \mathrm{P}$ and $\mathrm{E} / \mathrm{P}$ than with expansion period $\mathrm{D} / \mathrm{P}$ and $\mathrm{E} / \mathrm{P}$

\section{Data and Descriptive Statistics}

We obtain S\&P 500 index monthly dividend, earnings, price, and value-weighted monthly return data, for the period: January, 1926 to December, 2016, from Robert Shiller's website [used by studies such as Fama and French [13]]. Our sample size is 1092 monthly observations.

Table 1. Descriptive Statistics

\begin{tabular}{lccccc}
\hline Variable & Mean & Median & Min. & Max. & Std. Dev \\
\hline Price & 378.25 & 94.01 & 4.43 & 2238.83 & 549.34 \\
Dividend & 8.26 & 3.14 & 0.44 & 45.70 & 10.12 \\
Earnings & 19.23 & 5.81 & 0.41 & 105.96 & 26.37 \\
Dividend / Price & 0.0383 & 0.0357 & 0.0108 & 0.1537 & 0.0173 \\
Earnings / Price & 0.0709 & 0.0619 & 0.0079 & 0.1695 & 0.0285 \\
Monthly Return & 0.0022 & 0.0040 & -0.1470 & 0.1500 & 0.0237 \\
\hline
\end{tabular}

Table 1 reports the descriptive statistics of the main variables used in the study. We obtain S\&P 500 index monthly dividend, earnings, and price data from Robert Shiller's website. The data is of monthly periodicity, from January 1926 to December 2016, resulting in a sample period of 1092 months.

Table 1 presents the descriptive statistics of the main variables used in the study. The mean S\&P 500 index level is 378.25 with a standard deviation of 549.34. The mean S\&P 500 index monthly dividend is 8.26 , with a minimum of 0.44 , a maximum of 45.70 and a standard deviation of 10.12. Additionally, the mean S\&P 500 index monthly earnings is 19.23 , with a minimum of 0.41 , a maximum of 105.96 and a standard deviation of 26.37 . The mean value-weighted monthly return of the S\&P 500 index is $0.22 \%$ with a standard deviation of $2.37 \%$.

Table 2 presents results of the $T$-test of the difference between means of the main variables in expansion periods and means of the main variables in recession periods. We divide the sample period into three subperiods. Panel A presents results for the first subperiod: January, 1926 to December, 1955. With the exception of the monthly return and $\mathrm{D} / \mathrm{P}$ there is no significant difference in the means of the variables. Additionally, the $\mathrm{D} / \mathrm{P}$ is significantly higher during the recession. Consistent with earlier discussions, we find that dividends increase and prices decrease from the expansion periods to the recession periods resulting in the $\mathrm{D} / \mathrm{P}$ increase. There is no significant difference in means of $\mathrm{E} / \mathrm{P}$.

Panel B of Table 2 presents results for the second subperiod: January, 1956 to December, 1985. The results are similar to that for the first subperiod; $E / P$ is significantly higher during the recession periods; earnings increase and prices decrease from the expansion periods to the recession periods resulting in the $\mathrm{E} / \mathrm{P}$ increase. Panel $\mathrm{C}$ of Table 2 presents results for the third subperiod: January, 1986 to December, 2016. Consistent with the first and second subperiods, $\mathrm{D} / \mathrm{P}$ is higher during recessions than expansion periods. However, E/P is significantly lower during the recession periods; earnings decrease and prices decrease from the expansion periods to the recession periods resulting in the E/P decrease. 
Table 2. Difference of Means

\begin{tabular}{|c|c|c|c|c|c|c|c|c|}
\hline \multicolumn{9}{|c|}{ Panel A: Period 1[1926-01 - 1955-12 ] } \\
\hline & \multicolumn{3}{|c|}{ Expansion $[\mathrm{E}][\mathrm{N}=256]$} & \multicolumn{3}{|c|}{ Recession $[\mathrm{R}][\mathrm{N}=104]$} & \multirow[b]{2}{*}{$\begin{array}{c}\text { Difference } \\
\text { of Means } \\
{[E-R]}\end{array}$} & \multirow[b]{2}{*}{$\begin{array}{c}\text { T-statistic of } \\
\text { Difference } \\
\text { (p-value) }\end{array}$} \\
\hline Variable & Mean & Median & Std. Dev. & Mean & Median & Std. Dev. & & \\
\hline Price & 16.74 & 14.63 & 7.8724 & 15.55 & 14.99 & 6.1708 & 1.1913 & $1.53(0.1279)$ \\
\hline Dividend & 0.84 & 0.69 & 0.3666 & 0.88 & 0.83 & 0.2419 & -0.0378 & $-1.15(0.2529)$ \\
\hline Earnings & 1.42 & 1.08 & 0.7923 & 1.31 & 1.16 & 0.6740 & 0.1092 & $1.32(0.1876)$ \\
\hline Dividend / Price & 0.0518 & 0.0501 & 0.0120 & 0.0622 & 0.0582 & 0.0212 & -0.0105 & $-4.75(0.000)$ \\
\hline Earnings / Price & 0.0846 & 0.0809 & 0.0276 & 0.0851 & 0.0745 & 0.0311 & -0.0005 & $-0.14(0.8856)$ \\
\hline Monthly Return & 0.0059 & 0.0060 & 0.0239 & -0.0044 & 0.0025 & 0.0450 & 0.0102 & $2.19(0.0301)$ \\
\hline \multicolumn{9}{|c|}{ Panel B: Period 2[1956-01 - 1985-12 ] } \\
\hline & \multicolumn{3}{|c|}{ Expansion [E] [N = 287] } & \multicolumn{3}{|c|}{ Recession [R] [N = 73] } & & \\
\hline Variable & Mean & Median & Std. Dev & Mean & Median & Std. Dev. & $\begin{array}{c}\text { Difference } \\
\text { of Means } \\
{[E-R]} \\
\end{array}$ & $\begin{array}{c}\text { T-statistic of } \\
\text { Difference } \\
\text { (p-value) }\end{array}$ \\
\hline Price & 96.82 & 94.70 & 35.0951 & 85.55 & 85.02 & 27.7319 & 11.2717 & $2.93(0.0040)$ \\
\hline Dividend & 3.65 & 3.07 & 1.8100 & 3.97 & 3.44 & 1.8676 & -0.3192 & $-1.31(0.1923)$ \\
\hline Earnings & 7.54 & 5.63 & 4.2748 & 8.65 & 8.36 & 4.6891 & -1.1051 & $-1.83(0.0702)$ \\
\hline Dividend / Price & 0.0367 & 0.0341 & 0.0075 & 0.0448 & 0.0431 & 0.0088 & -0.00805 & $-7.17(0.000)$ \\
\hline Earnings / Price & 0.07467 & 0.0633 & 0.0243 & 0.0953 & 0.0889 & 0.0292 & -0.0206 & $-5.56(0.000)$ \\
\hline Monthly Return & 0.0019 & 0.0020 & 0.0153 & -0.0018 & -0.0040 & 0.0247 & 0.00367 & $1.21(0.2296)$ \\
\hline \multicolumn{9}{|c|}{ **Panel C: Period 3[1986-01 -2016-12] } \\
\hline & \multicolumn{3}{|c|}{ Expansion [E][N = 335] } & \multicolumn{3}{|c|}{ Recession [R][N = 37] } & & \\
\hline Variable & Mean & Median & Std. Dev & Mean & Median & Std. Dev. & $\begin{array}{c}\text { Difference } \\
\text { of Means } \\
{[E-R]} \\
\end{array}$ & $\begin{array}{c}\text { T-statistic of } \\
\text { Difference } \\
\text { (p-value) }\end{array}$ \\
\hline Price & 1010.44 & 1090.82 & 552.2 & 935.77 & 1040.94 & 388.8 & 74.67 & $1.06(0.296)$ \\
\hline Dividend & 19.67 & 16.22 & 9.72 & 21.10 & 25.59 & 7.30 & -1.43 & $-0.87(0.386)$ \\
\hline Earnings & 49.29 & 39.72 & 28.34 & 32.13 & 27.10 & 17.78 & 17.16 & $5.18(0.000)$ \\
\hline Dividend / Price & 0.022 & 0.020 & 0.007 & 0.0255 & 0.0247 & 0.009 & -0.003 & $-2.90(0.004)$ \\
\hline Earnings / Price & 0.051 & 0.052 & 0.0135 & 0.038 & 0.039 & 0.0188 & 0.013 & $4.11(0.000)$ \\
\hline Monthly Return & 0.0034 & 0.0050 & 0.0178 & -0.0061 & -0.0040 & 0.0276 & 0.0095 & 2.03(0.049) \\
\hline
\end{tabular}

Table 2 presents results of the $T$-tests of the difference of means of the main variables in expansion and recession periods. We divide the sample period into three subperiods and present the $T$-test of the difference between means.

\section{D/P and E/P and Return Predictability}

To develop a model of asset return predictability, we review the theoretical relationships between valuation ratios and expected returns. Fama and French [14] documents dividend yield is a predictor of future stock returns, particularly, predicts long-term business conditions. Employing the multi-period forecasting test of Fama and French [14];

$$
\begin{aligned}
& \sum_{n=1}^{N} \frac{r_{t+N}}{N}=a+b_{1} \times \log \left[\frac{D}{P}\right]_{t}+u_{t+N, t} \\
& \sum_{n=1}^{N} \frac{r_{t+N}}{N}=a+b_{1} \times \log \left[\frac{E}{P}\right]_{t}+u_{t+N, t}
\end{aligned}
$$

where $r_{t+N}$ is the S\&P 500 monthly continuously compounded excess return computed as the continuously compounded S\&P 500 value-weighted monthly return minus the monthly continuously compounded one-month Treasury bill rate, $\boldsymbol{b}_{1}$ is a slope coefficient, $\mathrm{N}$ is the forecasting horizon in months, $\mathrm{D} / \mathrm{P}$ is the dividend-price ratio, E/P is the earnings-price ratio and $u_{t+N, t}$ is the regression residual. We estimate monthly regressions for different time horizons: $\mathrm{N}=12,18$, and 24 months.

Table 3 panel A presents the results of the multi-period forecasting model for the full sample. The adjusted $\mathrm{R}^{2}$ from the univariate regressions show that $\mathrm{D} / \mathrm{P}$ and $\mathrm{E} / \mathrm{P}$ explain $2 \%$ to $4 \%$ of the variability in future returns: market returns of 12-month horizon to 24-month horizon, respectively. Next, we partition the full sample period into expansion and regression periods, rerun our primary regressions: (1) and (2), and present the results in panel B of Table 3. Consistent with our hypothesis, with the exception of the 24-month horizon regression for $\mathrm{E} / \mathrm{P}$, the adjusted $\mathrm{R}^{2}$ from the univariate regressions are higher for recession periods than for the expansion periods.

Next, we divide the full sample period into three subperiods again, partition each subperiod into expansion and regression periods, rerun our primary regressions: (1) and (2), and tabulate the results in panels $\mathrm{C}$ to $\mathrm{E}$ of Table 3. Panel C suggests that during the first subperiod; January, 1926 to December, 1955, consistent with the full sample, adjusted $\mathrm{R}^{2}$ from the univariate regressions are higher for the recession periods than for the expansion periods. Particularly, E/P has higher explanatory power than $\mathrm{D} / \mathrm{P}$ in this subperiod.

Panel D of Table 3 depicts the second subperiod; January, 1956 to December, 1985. Converse to the full sample, adjusted $\mathrm{R}^{2}$ from the univariate regressions are lower for the recession periods than for the expansion period. Panel E of Table 3 shows that during the third subperiod; January, 1986 to December, 2016, consistent with the full sample, adjusted $\mathrm{R}^{2}$ from the univariate regressions are higher for the recession periods than for the expansion periods. Additionally, D/P has higher explanatory power than $\mathrm{E} / \mathrm{P}$ in this subperiod. 
Table 3. Univariate Forecasting Regressions with Valuation Ratios

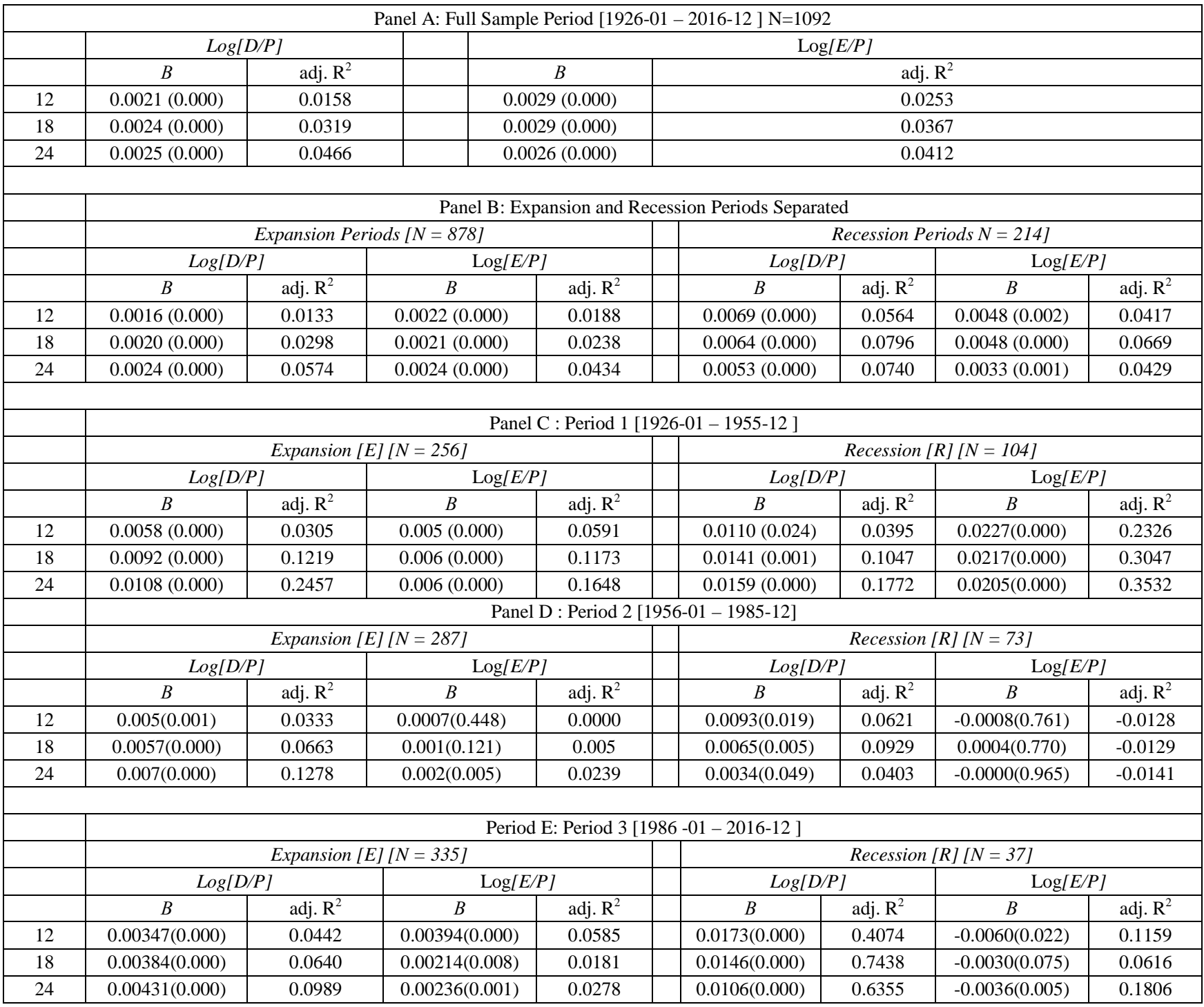

This table presents the univariate forecasting regression results in equation (1) and (2).

$$
\begin{gathered}
\sum_{n=1}^{N} \frac{r_{t+N}}{N}=a+b \times \log D / P_{t}+u_{t+N, t} \\
\sum_{n=1}^{N} \frac{r_{t+N}}{N}=a+b \times \log E / P_{t}+u_{t+N, t}
\end{gathered}
$$

where $r_{t+N}$ is the S\&P 500 monthly continuously compounded excess return computed as the continuously compounded S\&P 500 value-weighted monthly return minus the monthly continuously compounded one-month Treasury bill rate, $\boldsymbol{b}$ is a slope coefficient, $\mathrm{N}$ is the forecasting horizon in months, and $u_{t+N, t}$ is the regression residual. We estimate monthly regressions for different time horizons: $\mathrm{N}=12,18$, and 24 months. $B$ is the slope coefficient from the OLS forecasting regressions. The adj. $\mathrm{R}^{2}$ is acquired from the OLS regression.

From the above discussion, the explanatory power of $\mathrm{D} / \mathrm{P}$ and $\mathrm{E} / \mathrm{P}$ for future returns varies by subperiod. To investigate these changes, we examine the trends in $\mathrm{D} / \mathrm{P}$, $\mathrm{E} / \mathrm{P}$, and the 24-month horizon future return for the full sample period as well as the subperiods.

Examining the trends, we find that $\mathrm{D} / \mathrm{P}, \mathrm{E} / \mathrm{P}$, and the 24-month horizon future market return move almost in tandem during the first two subperiods, peaks toward the end of recession periods. However, during the third subperiod, E/P; trending differently than $\mathrm{D} / \mathrm{P}$ and 24-month horizon future market return; declines during recessions, and is consistent with the negative regression coefficient for $\mathrm{E} / \mathrm{P}$ recessions in subperiod 3. D/P declines from levels from the previous subperiods but is still in tandem with the 24-month horizon future market return.

Consistent with our primary hypothesis, D/P and the 24-month horizon future market return trend differently during expansion periods, but the trends are reset into tandem during recession periods. However, for the E/P and the 24-month horizon future market return, the trend is similar to $\mathrm{D} / \mathrm{P}$ for the first two subperiods, but during the third subperiod, E/P declines during recessions. These trends explain the higher explanatory power of $\mathrm{D} / \mathrm{P}$ and E/P during recessions. Finally, we test the significance of the difference in explanatory power of D/P and E/P between recession and expansion periods in the next section. 


\section{D/P and E/P and Recession Return Predictability}

As a robustness check, we expand the multi-period forecasting test of Fama and French [14] into a multivariate regression model to re-examine our primary hypothesis.

$$
\begin{aligned}
\sum_{n=1}^{N} \frac{r_{t+N}}{N}= & a+b_{1} \times \log \left[\frac{D}{P}\right]_{t}+b_{2} \times R E S_{t} \\
& +b_{3} \times R E S_{t} * \log \left[\frac{D}{P}\right]_{t}+u_{t+N, t} \\
\sum_{n=1}^{N} \frac{r_{t+N}}{N}= & a+b_{1} \times \log \left[\frac{E}{P}\right]_{t}+b_{2} \times R E S_{t} \\
& +b_{3} \times R E S_{t} * \log \left[\frac{E}{P}\right]_{t}+u_{t+N, t}
\end{aligned}
$$

where $r_{t+N}$ is the S\&P 500 monthly continuously compounded excess return computed as the continuously compounded S\&P 500 value-weighted monthly return minus the monthly continuously compounded one-month Treasury bill rate, $\boldsymbol{b}_{1}$ is a slope coefficient, $\mathrm{N}$ is the forecasting horizon in months, $\mathrm{D} / \mathrm{P}$ is the dividend-price ratio, $\mathrm{E} / \mathrm{P}$ is the earnings-price ratio and $u_{t+N, t}$ is the regression residual. $R E S_{t}$ is a binary variable, and is set to 1 for a recession month, and zero otherwise. We estimate monthly regressions for different time horizons: $\mathrm{N}=12$, 18 , and 24 months.

The results are presented in Table 4. Panel A presents the results for the full sample. The coefficient estimate for the recession and $\log (\mathrm{D} / \mathrm{P})$ interaction term is positive and statistically significant for all future return horizons, confirming that $\mathrm{D} / \mathrm{P}$ has higher predictive power during recession periods than during economic growth periods. With the exception of the 24-month future return horizon, the coefficient estimate for the recession and $\log (\mathrm{E} / \mathrm{P})$ interaction term is also positive and statistically significant for future return horizons, supporting that E/P has higher

\begin{tabular}{|c|c|c|c|c|c|c|c|c|}
\hline & \multicolumn{8}{|c|}{ Panel A: Full Sample [N = 1092] } \\
\hline & \multicolumn{4}{|c|}{$D / P$} & \multicolumn{4}{|c|}{$E / P$} \\
\hline $\mathrm{N}$ & RES & $R L D P$ & $L D P$ & adj. $\mathrm{R}^{2}$ & RES & $R L E P$ & LEP & adj. $\mathrm{R}^{2}$ \\
\hline 12 & $0.0147(0.000)$ & $0.0053(0.000)$ & $0.0016(0.005)$ & 0.0384 & $0.0058(0.064)$ & $0.0027(0.020)$ & $0.0022(0.001)$ & 0.0336 \\
\hline 18 & $0.0122(0.000)$ & $0.0044(0.000)$ & $0.0020(0.000)$ & 0.0545 & $0.0062(0.016)$ & $0.0027(0.005)$ & $0.0021(0.000)$ & 0.0455 \\
\hline \multirow[t]{3}{*}{24} & $0.0076(0.009)$ & $0.0029(0.000)$ & $0.0024(0.000)$ & 0.0670 & $0.0015(0.491)$ & $0.0009(0.263)$ & $0.0024(0.000)$ & 0.0451 \\
\hline & \multicolumn{8}{|c|}{ Panel B: Period 1 [1926-01 - 1955-12 ] [N = 360] } \\
\hline & \multicolumn{4}{|c|}{$D / P$} & \multicolumn{4}{|c|}{$E / P$} \\
\hline $\mathrm{N}$ & RES & $R L D P$ & $L D P$ & adj. $\mathrm{R}^{2}$ & RES & $R L E P$ & LEP & adj. $R^{2}$ \\
\hline 12 & $0.0105(0.391)$ & $0.0052(0.216)$ & $0.0058(0.033)$ & 0.0566 & $0.0404(0.000)$ & $0.0173(0.000)$ & $0.0053(0.002)$ & 0.1876 \\
\hline 18 & $0.0096(0.330)$ & $0.0049(0.150)$ & $0.0092(0.000)$ & 0.1285 & $0.0365(0.000)$ & $0.0155(0.000)$ & $0.0061(0.000)$ & 0.2531 \\
\hline \multirow[t]{3}{*}{24} & $0.0097(0.235)$ & $0.0049(0.081)$ & $0.0110(0.000)$ & 0.2167 & $0.0339(0.000)$ & $0.0144(0.000)$ & $0.0061(0.000)$ & 0.3040 \\
\hline & \multicolumn{8}{|c|}{ Panel C: Period 2 [1956-01 - 1985-12] [N = 360] } \\
\hline & \multicolumn{4}{|c|}{$D / P$} & \multicolumn{4}{|c|}{$E / P$} \\
\hline $\mathrm{N}$ & RES & $R L D P$ & $L D P$ & adj. $\mathrm{R}^{2}$ & RES & $R L E P$ & $L E P$ & adj. $R^{2}$ \\
\hline 12 & $0.0166(0.139)$ & $0.0044(0.215)$ & $0.0049(0.002)$ & 0.1163 & $0.0001(0.985)$ & $-0.0015(0.505)$ & $0.0007(0.481)$ & 0.0728 \\
\hline 18 & $0.0047(0.585)$ & $0.0008(0.771)$ & $0.0057(0.000)$ & 0.1579 & $0.0010(0.820)$ & $-0.0009(0.621)$ & $0.0013(0.116)$ & 0.0952 \\
\hline \multirow[t]{3}{*}{24} & $-0.0089(0.189)$ & $-0.0031(0.153)$ & $0.0065(0.000)$ & 0.1577 & $-0.0033(0.351)$ & $-0.0020(0.161)$ & $0.0019(0.004)$ & 0.0657 \\
\hline & \multicolumn{8}{|c|}{ Panel D: Period 3 [ 1986-01 - 2016-12] [N = 372] } \\
\hline & \multicolumn{4}{|c|}{$D / P$} & \multicolumn{4}{|c|}{$E / P$} \\
\hline $\mathrm{N}$ & RES & $R L D P$ & $L D P$ & adj. $\mathrm{R}^{2}$ & $R E S$ & $R L E P$ & $L E P$ & adj. $R^{2}$ \\
\hline 12 & $0.046(0.000)$ & $0.0138(0.000)$ & $0.00347(0.000)$ & 0.2225 & $-0.03759(0.000)$ & $-0.00993(0.000)$ & $0.00394(0.000)$ & 0.1450 \\
\hline 18 & $0.03613(0.000)$ & $0.01701(0.000)$ & $0.00384(0.000)$ & 0.2223 & $-0.02015(0.000)$ & $-0.00514(0.001)$ & $0.00214(0.012)$ & 0.0690 \\
\hline 24 & $0.02133(0.002)$ & $0.00628(0.000)$ & $0.0007(0.000)$ & 0.1838 & $-0.02103(0.000)$ & $-0.00594(0.000)$ & $0.00236(0.002)$ & 0.0603 \\
\hline
\end{tabular}
predictive power during recession periods than during economic growth periods.

Table 4. Multivariate Forecasting Regressions with Valuation Ratios and Business Cycle Variable

This table presents the multivariate forecasting regression results in equation (9).

$$
\begin{aligned}
& \sum_{n=1}^{N} \frac{r_{t+N}}{N}=a+b_{1} \times \log \left[\frac{D}{P}\right]_{t}+b_{2} \times R E S_{t}+b_{3} \times R E S_{t} * \log \left[\frac{D}{P}\right]_{t}+u_{t+N, t} \\
& \sum_{n=1}^{N} \frac{r_{t+N}}{N}=a+b_{1} \times \log \left[\frac{E}{P}\right]_{t}+b_{2} \times R E S_{t}+b_{3} \times R E S_{t} * \log \left[\frac{E}{P}\right]_{t}+u_{t+N, t}
\end{aligned}
$$

where $r_{t+N}$ is the monthly continuously compounded excess return computed as the monthly continuously compounded return on the value-weighted market return including dividends from CRSP minus the monthly continuously compounded one-month Treasury bill rate, $\boldsymbol{X}_{t}$ is the matrix of prediction variables, $\boldsymbol{b}$ is the matrix of slopes coefficients, $\mathrm{N}$ is the forecasting horizon in months, and $u_{t+N, t}$ is the regression residual. We estimate monthly regressions for different time horizons: $\mathrm{N}=12,18$, and 24 months. $B$ is the slope coefficient from the OLS forecasting regressions and p-value is reported also. The adj. $\mathrm{R}^{2}$ is acquired from the OLS regression. P-values are in parenthesis. 
Panels B, C, and D of Table 4, present the results of the multivariate regression for the subperiods. For subperiod 1 [January, 1926 to December, 1955], the coefficient estimate for the recession - $\log (\mathrm{E} / \mathrm{P})$ interaction term is statistically significant for all future return horizons, confirming that $\mathrm{E} / \mathrm{P}$ has higher predictive power during recession periods than during economic growth periods. Consistent with our earlier findings, the coefficient estimates for the recession and $\log (\mathrm{D} / \mathrm{P})$ interaction term are not statistically significant for subperiod 1 [January, 1926 to December, 1955]. For subperiod 2 [January, 1956 to December, 1985], there is no difference in predictive power between recession and expansionary periods for neither D/P nor E/P.

The results for subperiod 3 [January, 1986 to December, 2016] are rather interesting and different from the earlier subperiods. The coefficient estimate for the recession and $\log (\mathrm{D} / \mathrm{P})$ interaction term is positive and statistically significant for all future return horizons, consistent with subperiod 1. However, the coefficient estimate for the recession and $\log (\mathrm{E} / \mathrm{P})$ interaction term is negative and statistically significant for future return horizons. Additionally, consistent with our findings from the univariate regressions, unlike earlier subperiods, for subperiod 3, there is a decrease in adjusted r-squared with increasing future return horizon, suggesting a decline in the predictive power of both $\mathrm{D} / \mathrm{P}$ and $\mathrm{E} / \mathrm{P}$.

\section{Conclusion}

In this study, we examine the differential predictive power of the dividend-price ratio $[\mathrm{D} / \mathrm{P}]$ and the earnings-price ratio $[\mathrm{E} / \mathrm{P}]$ for future stock returns during recessions versus during expansionary periods. Consistent with extant research such as Ang and Bekaert [3], we find that dividends do not decrease but prices decrease from the expansion periods to the recession periods resulting in the $\mathrm{D} / \mathrm{P}$ increase during recessions. This increase in $\mathrm{D} / \mathrm{P}$ during recessions is correlated with the increase in market returns following recessions.

There is no significant difference in means of $E / P$ between recession and expansion periods. However, for the third subperiod: January, 1986 to December, 2016, E/P is significantly lower during the recession periods; earnings as well as prices decrease from the expansion periods to the recession periods resulting in the $E / P$ decrease. This decrease in $\mathrm{E} / \mathrm{P}$ during recessions in the third subperiod is correlated with the increase in market returns following recessions and is consistent with the negative regression coefficients for $\mathrm{E} / \mathrm{P}$.

Additionally, we find that the explanatory power of $\mathrm{D} / \mathrm{P}$ and $\mathrm{E} / \mathrm{P}$ for future market returns varies with time. $\mathrm{D} / \mathrm{P}$,
$\mathrm{E} / \mathrm{P}$, and future market returns move together during the first two subperiods, peaking toward the end of recession periods. Particularly, D/P and future market return trend differently during expansion periods, but the trends are reset into tandem during recession periods.

The trends in $\mathrm{D} / \mathrm{P}$ and $\mathrm{E} / \mathrm{P}$ : the decrease in dividends relative to prices, and the decrease in E/P during recessions in the last 31 years [1986 to 2016], explain the differential predictive powers and also explain why predictive regressions using the last 100 years of data present conflicting results.

Future research could examine the differential predictive power of other valuation ratios.

\section{References}

[1] Rapach, David E., Jack K. Strauss, and Guofu Zhou (2010) “Outof-sample equity premium prediction: Combination forecasts and links to the real economy.” Review of Financial Studies (23), pp. 821-862.

[2] Dangl Thomas and Michael Halling (2012). "Predictive regressions with time-varying coefficients.” Journal of Financial Economics (106), pp 157-181.

[3] Ang Andrew and Geert Bekaert (2007) "Stock Return Predictability: Is it There?” The Review of Financial Studies (20), pp. 651-707.

[4] Lanne Markku (2002) 'Testing The Predictability Of Stock Returns." The Review of Economics and Statistics (84), pp. 407-415.

[5] Torous, Walter, Rossen Valkanov, and Shu Yan (2005). On Predicting Stock Returns with Nearly Integrated Explanantory Variables, Journal of Business 77, 380-403.

[6] Campbell, John Y. and Yogo, Motohiro (2005). "Efficient Tests of Stock Return Predictability.” Journal of Financial Economics (81), 27-60.

[7] Cujean, Julien and Hasler, Michael (2017). "Why Does Return Predictability Concentrate in Bad Times?" Journal of Finance (72), pp. 2717-2758.

[8] Nieuwerburgh Stijn Van and Laura Veldkamp (2006). "Learning asymmetries in real business cycles"Journal of Monetary Economics (53), pp. 753-772.

[9] Coakley, Jerry and Ana-Maria Fuertes (2006). "Valuation Ratios and Price Deviations from Fundamentals”. Journal of Banking \& Finance (30), pp. 2325-2346.

[10] Gray Stephen F. (1996). "Modeling the conditional distribution of interest rates as a regime-switching process." Journal of Financial Economics (42), pp. 27-62.

[11] Lee, Wayne Y., Christine X. Jiang and Daniel C. Indro. (2002). "Stock market volatility, excess returns, and the role of investor sentiment.” Journal of Banking \& Finance (26), pp. 2277-2299.

[12] Kim, Jae H., Shamsuddin, Abul, and Lim, Kian-Ping. (2011). "Stock return predictability and the adaptive markets hypothesis: Evidence from century-long U.S. data," Journal of Empirical Finance, (18), pp. 868-879.

[13] Fama Eugene F. and Kenneth R. French. (2002). "Testing TradeOff and Pecking Order Predictions about Dividends and Debt." The Review of Financial Studies (15), pp. 1-33.

[14] Fama, Eugene F, and Kenneth R. French. (1989). "Business conditions and expected returns on stocks and bonds.” Journal Financial Economics (25) 23-49. 